Article

\title{
Design and Analysis of Rotor Shapes for IPM Motors in EV Power Traction Platforms
}

\author{
Myeong-Hwan Hwang ${ }^{1,2}$, Jong-Ho Han ${ }^{1}$, Dong-Hyun Kim ${ }^{1}$ and Hyun-Rok Cha ${ }^{1, *}$ \\ 1 EV Components \& Materials R\&D Group, Korea Institute of Industrial Technology, 6 Cheomdan-gwagiro \\ 208 beon-gil, Buk-gu, Gwangju 61012, Korea; han9215@kitech.re.kr (M.-H.H.); \\ jonghohan@kitech.re.kr (J.-H.H.); bjiuh2608@kitech.re.kr (D.-H.K.) \\ 2 Department of Electrical Engineering, Chonnam National University, 77 Youngbong-ro, Buk-gu, \\ Gwangju 61186, Korea \\ * Correspondence: hrcha@kitech.re.kr; Tel.: +82-62-600-6212
}

Received: 7 September 2018; Accepted: 27 September 2018; Published: 29 September 2018

check for updates

\begin{abstract}
The recent increase in the use of permanent magnet rotor motors underlines the importance of designing a rotor with an interior permanent magnet (IPM) structure, high power, and high efficiency. This study analyzed the rotor shapes of IPM motors for electric vehicles. Five types of motor rotors for automobiles were analyzed, including two hybrid vehicles. In order to minimize the number of variables in the analysis, the size of the motor stators was fixed and only the rotor shapes were modified to compare torque, torque ripple, efficiency and back-electromotive voltage. When the motor properties were compared as a function of rotor shape, the rotor shape with the smallest magnet volume exhibited excellent results for torque, efficiency and torque ripple.
\end{abstract}

Keywords: traction motor; electric vehicle; interior permanent magnet; vehicle motor; electromagnetic field analysis; cogging torque

\section{Introduction}

Various regulations in the car industry are being introduced to respond to environmental changes caused by global warming [1]; for example, electrically powered powertrains have been developed to reduce exhausted gas and improve the power efficiency of vehicles. As a result, the demand for electrical vehicles, which are recognized as environmentally friendly, continues to surge [2]. Electric traction motors, which represent the most essential of technologies among this changeover, are needed owing to their wide velocity, high power density, and high efficiency [3-5].

With advances in electrical machines and recent control technologies, AC machines have become mainstream (as opposed to DC machines) and now dominated the traction machine market. Both synchronous and asynchronous AC machines are used in commercially available electric-powered vehicles. Induction machines contain the most mature manufacturing technologies, those that that have been developed over a number of decades [5,6]. Induction machine technologies are also relatively lower in cost and offer easier control. However, the conductors of the rotor increase the rotor copper losses and also the cooling requirement. The conductor usually applies to a lower operating efficiency as compared with permanent magnet synchronous machines (PMSM); therefore, the majority of automotive manufacturers are choosing appropriate PMSM for the traction motor in the vehicle [7].

Among the electric traction motors, interior permanent magnet (IPM) motors, which include rotors with embedded magnets, are increasingly being used as the driving motors for electric vehicles. The advantages of an IPM motor include its wide velocity and torque variation, high power, light weight, and energy efficiency. The most influential factor affecting the performance of IPM motors is 
the rotor shape. Therefore, determining an appropriate IPM rotor shape is essential for designing a highly functional driving motor for electrical vehicles (EVs) [8-11].

As the importance of IPM motors for EVs continues to increase, various rotor structures have been proposed. Only a few studies have comprehensively compared the rotor shapes of IPM motors in order to establish a design standard. Accordingly, this study attempted to identify an appropriate shape for an IPM rotor for EVs by analyzing three models of major EV motor manufacturers currently in mass production, as well as two hybrid models. Based on the results of this study, we plan to present a design standard for rotor shapes that appropriately reflects the requirements of EVs [12].

However, the critical problem is that analysis and improvement could waste both time and cost. Therefore, the magnet arrangement of high-power IPM rotor shape should be analyzed and developed to reduce time and cost. The torque and rotation speed were analyzed according to rotor shape. Each motor stator had the same size and winding, with a motor rotor of the same size, but with a different arrangement of magnets [13].

Many studies of rotor shape have aimed to reduce design and analysis time [14]. However, this study focused on time reduction when selecting the design concept. We believe that the results of study will improve design efficiency by decreasing the initial design time and enhancing torque, power, and efficiency, depending on the shape of IPM rotor.

The remainder of this paper is organized as follows. The main parameters of the IPM motor rotor and five analysis rotor models are introduced in Section 2, followed by a comparison of the basic characteristics of each rotor in Section 3. The torque and efficiency of rotors are analyzed, in Section 4. Finally, conclusions are given in Section 5

\section{Analysis Models of IPM Motors}

To analyze the characteristics of IPM motors as a function of rotor shape, the outer diameter of each rotor was fixed to ensure the same conditions and to minimize the number of variables. In addition, the magnet arrangement of the rotor was adjusted to standardize the size and shape of the stator and the windings so that the properties were analyzed under similar conditions. To ensure the accuracy of the analysis using different magnet arrangements and rotor shapes, the rotor shapes and ratios typical of actual cars were maintained as much as possible.

Rotor shapes, shown in Figure 1, are general shapes, and this study analyzed each characteristic depending on shape. Additionally, Figure 1d,e was included and analyzed, because the V-shape has a smaller magnet volume than other general shapes [15].

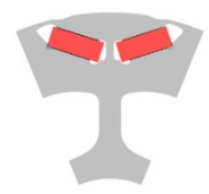

(a)

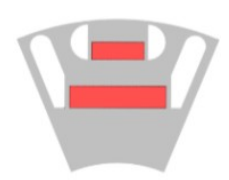

(b)

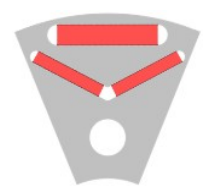

(c)

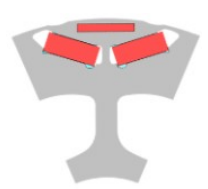

(d)

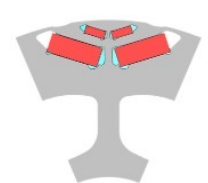

(e)

Figure 1. Interior Permanent Magnet Synchronous Motor Design Trend: (a) V-shaped rotor from manufacturer $\mathrm{T}$; (b) double magnet shape from manufacturer $\mathrm{V}$; (c) delta shape from manufacturer $\mathrm{V}$; (d) hybrid delta shape based on the $\mathrm{V}$ shape from both manufacturer $\mathrm{T}$ and manufacturer $\mathrm{N}$; (e) hybrid double $\mathrm{V}$ shape from both manufacturer $\mathrm{T}$ and manufacturer $\mathrm{V}$. These five shapes have been previously analyzed [16].

\subsection{Stator Model for Analyzing Rotor Properties}

Table 1 presents the specifications of the stator model used in this study as an IPM motor. The number of slots was 48 and the rated voltage is DC $650 \mathrm{~V}$. The same electrical current was applied to each motor for analysis. The maximum rated current was $200 \mathrm{~A}$. Table 1 also provides a cross-sectional view of the 48 slot stator. The outer diameter of an IMP motor stator is $200 \mathrm{~mm}$. In order to form a sinusoidal back-EMF (B-EMF) at the stator, distributed windings were designed. As a space factor 
of $40 \%$ or below is known to enable windings, $36.80 \%$ was adopted for this design by considering the insulation thickness. In addition, nine $0.7 \mathrm{~mm}$ coils were wound 10 turns to reduce the current density [17].

Table 1. Main parameters of stator.

\begin{tabular}{cccc}
\hline 48 Slot Stator & Parameters & Unit & Value \\
\hline & Number of Slots & Slot & 48 \\
Outside Diameter & $\mathrm{mm}$ & 200 \\
Inside Diameter & $\mathrm{mm}$ & 122 \\
Stack Length & $\mathrm{mm}$ & 50 \\
Air Gap & $\mathrm{mm}$ & 0.7 \\
& Turns & 10 \\
& Number of Turns & Turns & 9 \\
& Phase Resistance & $\mathrm{m} \Omega$ & 84.9693 \\
& Slot Fill Factor & $\%$ & 36.80 \\
& Coil Pitch & & 6 \\
\hline
\end{tabular}

\subsection{Analysis of Rotor Properties}

The outer diameter of the motor rotor was designed to be $120.6 \mathrm{~mm}$ for all models and the air gap was $0.7 \mathrm{~mm}$. Figure 2 illustrates the shapes of the five different magnets analyzed in this study. We chose to analyze the three most representative shapes of IPM rotors, along with two improved models that used additional magnets. As Table 2 shows, all rotors in this study had an outside diameter of $120 \mathrm{~mm}$, an air gap of $0.7 \mathrm{~mm}$, and eight magnet poles [18-20].

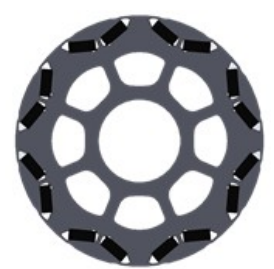

(a)

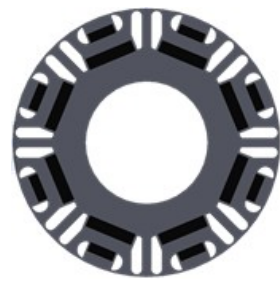

(b)

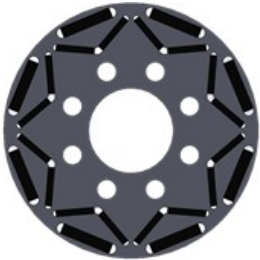

(c)

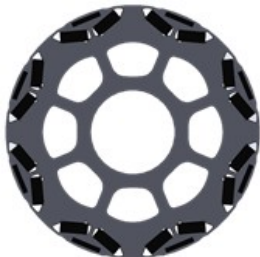

(d)

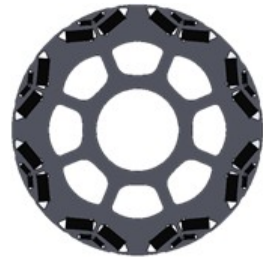

(e)

Figure 2. Five different shapes of Interior Permanent Magnet (IPM) rotors: (a) V shape from manufacturer $\mathrm{T}$; (b) double magnet shape from manufacturer $\mathrm{V}$; (c) delta shape with a bar magnet in a V shape; and (d,e) improved shapes using a delta shape and a double V shape, respectively.

Table 2. Comparison of outer diameter and air gap of rotor.

\begin{tabular}{cccccc}
\hline & $\begin{array}{c}\text { V-Shape } \\
\text { (Manufacturer T) }\end{array}$ & $\begin{array}{c}\text { Double } \\
\text { Magnet-Shape } \\
\text { (Manufacturer V) }\end{array}$ & $\begin{array}{c}\text { Delta-Shape } \\
\text { (Manufacturer N) }\end{array}$ & $\begin{array}{c}\text { Improved } \\
\text { Model (T+N } \\
\text { Delta Shape) }\end{array}$ & $\begin{array}{c}\text { Improved Model } \\
\text { (T+V Double } \\
\text { V Shape) }\end{array}$ \\
\hline $\begin{array}{c}\text { Number of } \\
\text { Magnet Poles }\end{array}$ & 8 & 8 & 8 & 8 & 8 \\
Outside (mm) & 120.6 & 120.6 & 120.6 & 120.6 & 120.6 \\
Air Gap (mm) & 0.7 & 0.7 & 0.7 & 0.7 & 0.7 \\
\hline
\end{tabular}

Since the volume of the magnet is the most influential factor in production cost and quality of an IPM motor, the magnet volumes for each design are compared in Table 3 and Figure 3. The magnet volume is directly related to manufacturing cost. So, the magnet volume is a key factor to reduce motor cost; furthermore, to achieve maximum torque per ampere (MTPA) by minimum volume of motor, optimization of the rotor shape and reduction of magnet volume is necessary [21,22]. The V-shaped rotor had the smallest magnet volume $\left(52,464 \mathrm{~mm}^{3}\right)$, while the delta-shaped rotor from manufacturer $\mathrm{N}$ had the largest magnet volume $\left(93,824 \mathrm{~mm}^{3}\right)$. As a small volume motor and high efficiency is critical to EVs, the smallest magnet volume would most likely be the most cost-effective motor design. 
Table 3. Analysis of rotor magnet volume.

\begin{tabular}{cccccc}
\hline & $\begin{array}{c}\text { V-Shape } \\
\text { (Manufacturer T) }\end{array}$ & $\begin{array}{c}\text { Double } \\
\text { Magnet-Shape } \\
\text { (Manufacturer V) }\end{array}$ & $\begin{array}{c}\text { Delta-Shape } \\
\text { (Manufacturer N) }\end{array}$ & $\begin{array}{c}\text { Improved } \\
\text { Model (T+N } \\
\text { Delta Shape) }\end{array}$ & $\begin{array}{c}\text { Improved Model } \\
\text { (T+V Double } \\
\text { V-Shape) }\end{array}$ \\
\hline $\begin{array}{c}\text { Magnet } \\
\text { Volume }\left(\mathrm{mm}^{3}\right)\end{array}$ & 52,464 & 63,200 & 93,824 & 74,864 & 60,736 \\
\hline
\end{tabular}

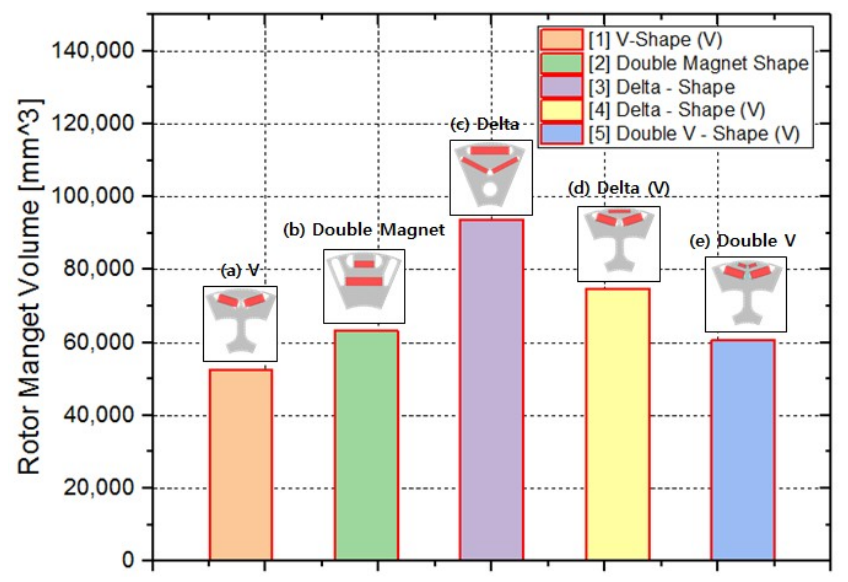

Figure 3. Comparison of Rotor Magnet Volume.

\section{Comparative Analysis}

In order to analyze the characteristics of IPM rotors according to their shape, three main factors were analyzed. Table 4 shows the critical factors analyzed in subsequent sections [23,24].

Table 4. Analysis of rotor magnet volume.

\begin{tabular}{lcc}
\hline No & Analysis Factor & Necessity of Analysis \\
\hline $\mathbf{1}$ & Back EMF & Determines the maximum range of motor rotation \\
$\mathbf{2}$ & Torque ripple or cogging torque & Very influential on noise and vibration \\
$\mathbf{3}$ & Torque & $\begin{array}{c}\text { As the magnitude of a force generated according to velocity, } \\
\text { torque is very influential in setting a domain of operation. } \\
\text { Closely related to the power consumption of a vehicle }\end{array}$ \\
$\mathbf{4}$ & Efficiency & Con
\end{tabular}

For analysis, we used the motor electromagnetic field analysis tool, "JMAG" (ver. 14.1), with data produced through simulation analysis.

\subsection{Analysis of B-EMF as a Function of Rotor Shapes}

A no-load voltage analysis was conducted by applying a rotational speed of $1000 \mathrm{rpm}$ to induce and analyze linear voltage values. Based on the results of B-EMF voltage analysis, a distributed winding was designed for the stator so that the B-EMF voltage waveforms were similar to a sinusoid. The V-shaped motor from manufacturer $\mathrm{T}$ was the most sinusoidal.

Table 5 presents B-EMF voltages and constants; a back-EMF analysis was performed for the five rotor shapes, as shown in Figure 4. The improved delta shape, which was based on the V-shape from manufacturer $\mathrm{T}$, had the highest B-EMF voltage $(28.68 \mathrm{~V})$, and the double magnet shape of manufacturer $\mathrm{T}$ showed the lowest B-EMF voltage $(20.80 \mathrm{~V})$. As the no-load voltage decreased, the no-load speed increased.

The V shape from manufacturer $\mathrm{T}$ utilized more magnetic flux than the other shapes; thus, it had a higher B-EMF voltage than that of the double magnet-shape. This indicates that the $\mathrm{V}$ shape using a small amount of current is suitable for generating high power. Moreover, as the $\mathrm{V}$ shape has a more sinusoidal waveform than the delta shape, it likely is more advantageous for minimizing torque ripples. 
Table 5. B-EMF voltage and constants.

\begin{tabular}{lccccc}
\hline & $\begin{array}{c}\text { V Shape } \\
\text { (Manufacturer T) }\end{array}$ & $\begin{array}{c}\text { Double Magnet } \\
\text { Shape } \\
\text { (Manufacturer V) }\end{array}$ & $\begin{array}{c}\text { Delta Shape } \\
\text { (Manufacturer N) }\end{array}$ & $\begin{array}{c}\text { Improved } \\
\text { Model (T+N } \\
\text { Delta Shape) }\end{array}$ & $\begin{array}{c}\text { Improved Model } \\
\text { (T+V Double } \\
\text { V-Shape) }\end{array}$ \\
\hline $\begin{array}{c}\text { B-EMF Voltage } \\
\text { (V_rms) }\end{array}$ & 27.13 & 20.80 & 27.9731 & 28.68 & 27.17 \\
$\begin{array}{c}\text { B-EMF Voltage } \\
\text { Constants } \\
\text { (V_rms/rpm) }\end{array}$ & 0.0271 & 0.0208 & 0.02797 & 0.02868 & 0.02717 \\
\hline
\end{tabular}

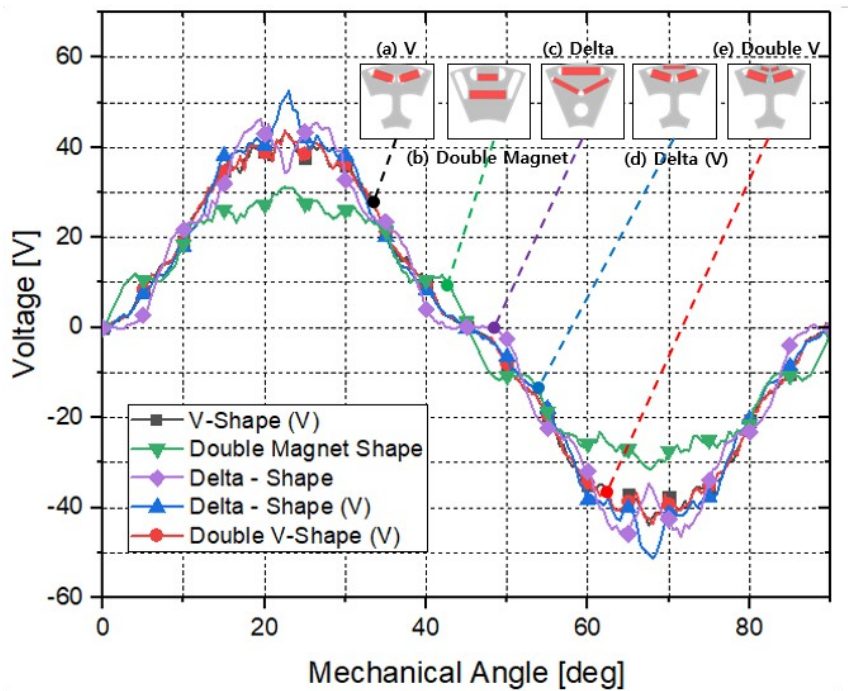

(a)

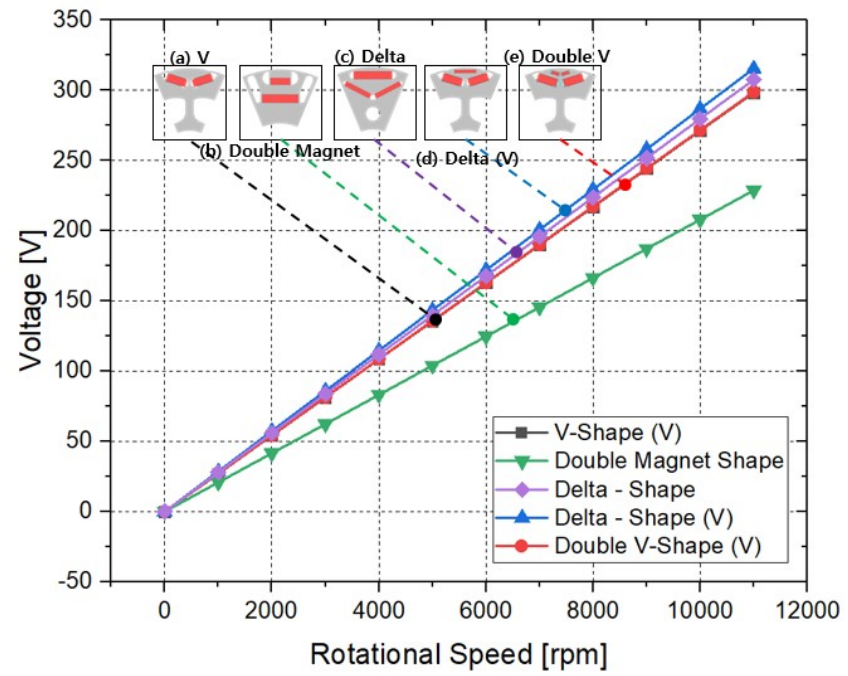

(b)

Figure 4. B-EMF Wave and No-Load Voltage: (a) B-EMF Wave; (b) B-EMF No-Load Voltage.

\subsection{Analysis of Cogging Torque and Torque Ripple}

Figure 5 shows the results of our electromagnetic field analysis for cogging torque and torque ripple. Since the improved delta $\mathrm{V}$ shape from manufacturer $\mathrm{T}$ was designed to arrange the magnets close to the stator in order to utilize magnetic flux more effectively, it had the highest cogging torque $(2.875 \mathrm{Nm})$. The best cogging torque was $0.9678 \mathrm{Nm}$, which was produced by the double magnet-shape from manufacturer V; the difference between this and the V-shaped rotor was $1.9 \mathrm{Nm}$. On the other hand, the cogging torque of the $\mathrm{V}$ shape was $1.898 \mathrm{Nm}$, but the improved double $\mathrm{V}$-shape was $1.798 \mathrm{Nm}$, a difference of just $0.1 \mathrm{Nm}$. Consequently, a double magnet-shaped rotor was shown to be advantageous for cogging torque, and using this shape would likely reduce design time [25]. 


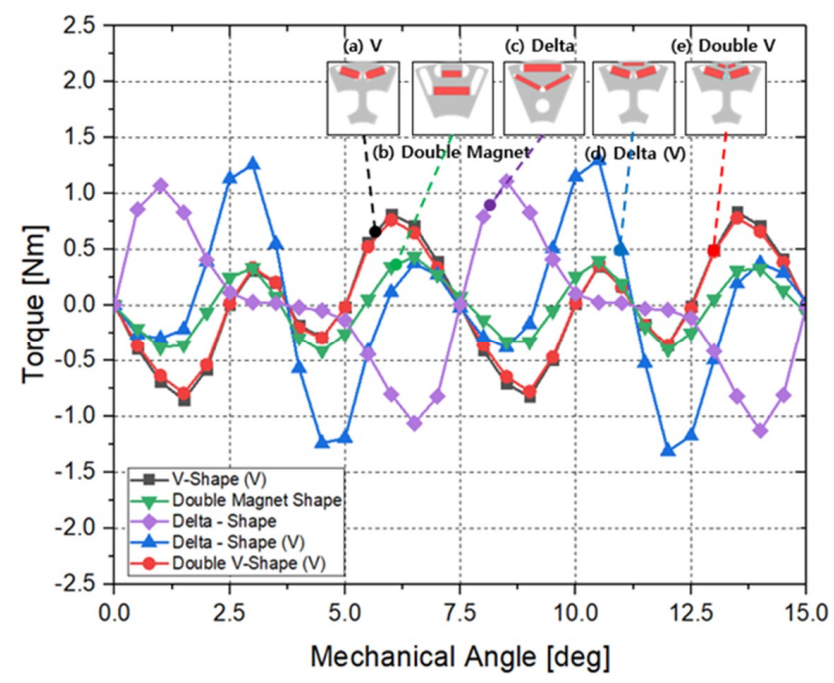

(a)

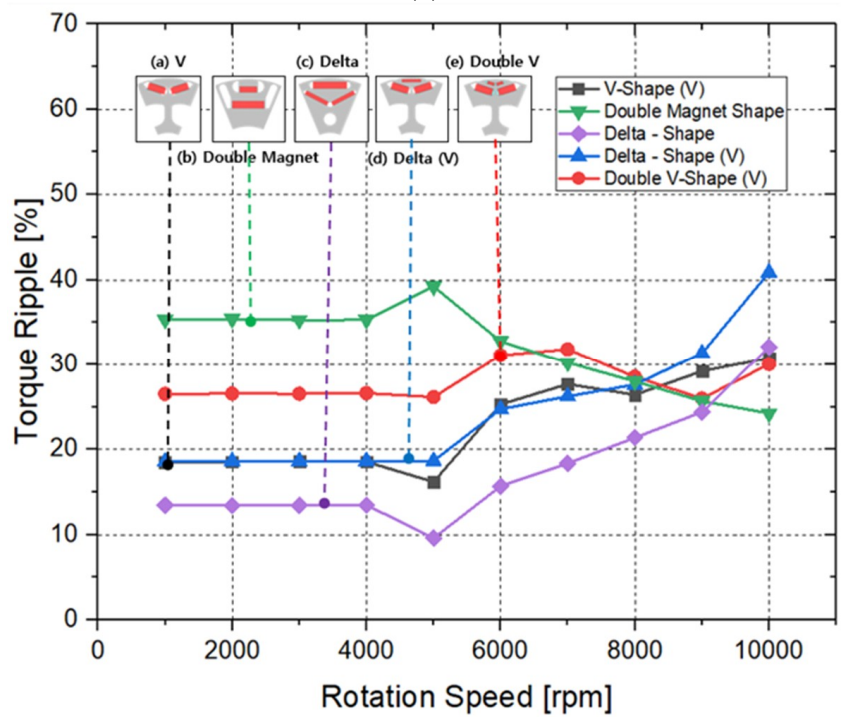

(b)

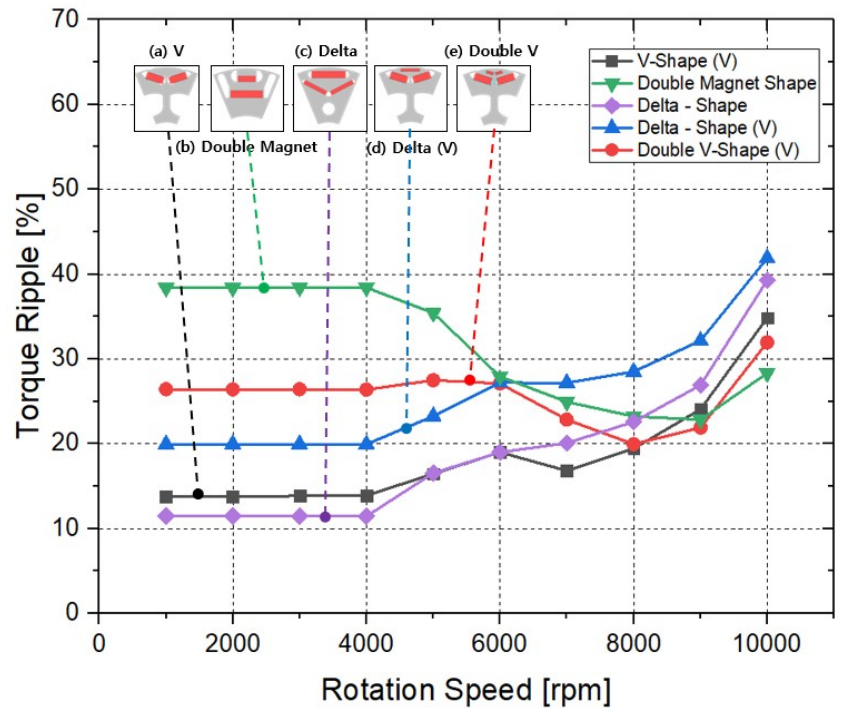

(c)

Figure 5. Analysis of cogging torque and torque ripple: (a) Comparison of torque ripples; (b) Comparison of torque ripples in the analysis of current source at $0^{\circ}$ current phase angle; (c) Comparison of torque ripples in the analysis of current source at $40^{\circ}$ current phase angle. 


\section{Results}

\subsection{Speed-Torque and Speed-Efficiency Analysis}

Another electromagnetic analysis was conducted by applying constant current at a variety of speeds. The range of the analysis was performed at 1000-10,000 rpm in consideration of B-EMF voltages. Initially, the analysis used magnet torques without controlling phase angles. As is widely known, magnetic reluctance in an IPM motor, i.e., saliency, an additional torque component is developed. By phase angle control, the torque is increased for a given current magnitude. Consequentially, maximum torque occurs for a current phase of $35-45^{\circ}$; this study conducted a comparative analysis at a current phase angle of $40^{\circ}$ in order to examine the characteristics of maximum torque.

As shown in Figure 6, in order to analyze the impact of the d-axis and the q-axis, the current of the q-axis was held at zero and the torque and efficiency due to the $\mathrm{d}$-axis were analyzed. The analysis showed that the delta-shape from manufacturer $\mathrm{N}$ had the highest torque $(77.65 \mathrm{Nm})$ because of its large magnet volume, and also because it has the widest magnet surface to generate an active magnetic flux. The V-shape, with the smallest magnet surface for generating active magnetic flux had a torque of $66.16 \mathrm{Nm}$, which was lower than that of the delta-shape by $11.49 \mathrm{Nm}$. Table 6 compares torque characteristics according to speed.

Table 6. Comparison of speed-torque characteristics according to rotor shapes (phase angle of $40^{\circ}$ ).

\begin{tabular}{cccccc}
\hline RPM & $\begin{array}{c}\text { V Shape } \\
\text { (Manufacturer } \\
\text { T) (Nm) }\end{array}$ & $\begin{array}{c}\text { Double } \\
\text { Magnet Shape } \\
\text { (Manufacturer } \\
\text { V) (Nm) }\end{array}$ & $\begin{array}{c}\text { Delta Shape } \\
\text { (Manufacturer } \\
\mathbf{N}) \mathbf{( N m )}\end{array}$ & $\begin{array}{c}\text { Improved } \\
\text { Model (T+N } \\
\text { Delta Shape) } \\
\mathbf{( N m )}\end{array}$ & $\begin{array}{c}\text { Improved } \\
\text { Model (T+V } \\
\text { Double } \\
\text { V-Shape) (Nm) }\end{array}$ \\
\hline 1000 & 66.12894 & 55.14583 & 77.65978 & 76.62068 & 71.49971 \\
2000 & 66.16147 & 55.16258 & 77.65832 & 76.62819 & 71.514 \\
3000 & 66.16877 & 55.16563 & 77.65658 & 76.63369 & 71.51918 \\
4000 & 66.16998 & 55.17346 & 77.66459 & 76.6316 & 71.52973 \\
5000 & 47.48419 & 38.72789 & 52.89918 & 53.16905 & 50.03325 \\
6000 & 28.56902 & 21.60797 & 29.9703 & 30.90529 & 29.45301 \\
7000 & 21.88614 & 16.23352 & 22.45951 & 23.38148 & 22.36065 \\
8000 & 17.2897 & 12.85844 & 17.62589 & 18.32735 & 17.55764 \\
9000 & 12.9869 & 9.78588 & 13.24661 & 13.66213 & 13.08482 \\
10,000 & 8.28681 & 6.32922 & 8.49809 & 8.67869 & 8.27965 \\
\hline
\end{tabular}

Next, the impact of the q-axis was analyzed by applying a current phase angle of $40^{\circ}$. When the current phase angle is controlled, magnet torques and reluctance torques are combined, which enabled us to identify the maximum torque. As shown in Figure 7, the improved double V shape from manufacturer $\mathrm{T}$ had the best torque $(107.98 \mathrm{Nm})$ and also exhibited high torques at rotational speeds of 5000-10,000 rpm. Data showing a comparison of speed-torque characteristics according to rotor shape (phase angle of $40^{\circ}$ ) is shown in Table 7. 


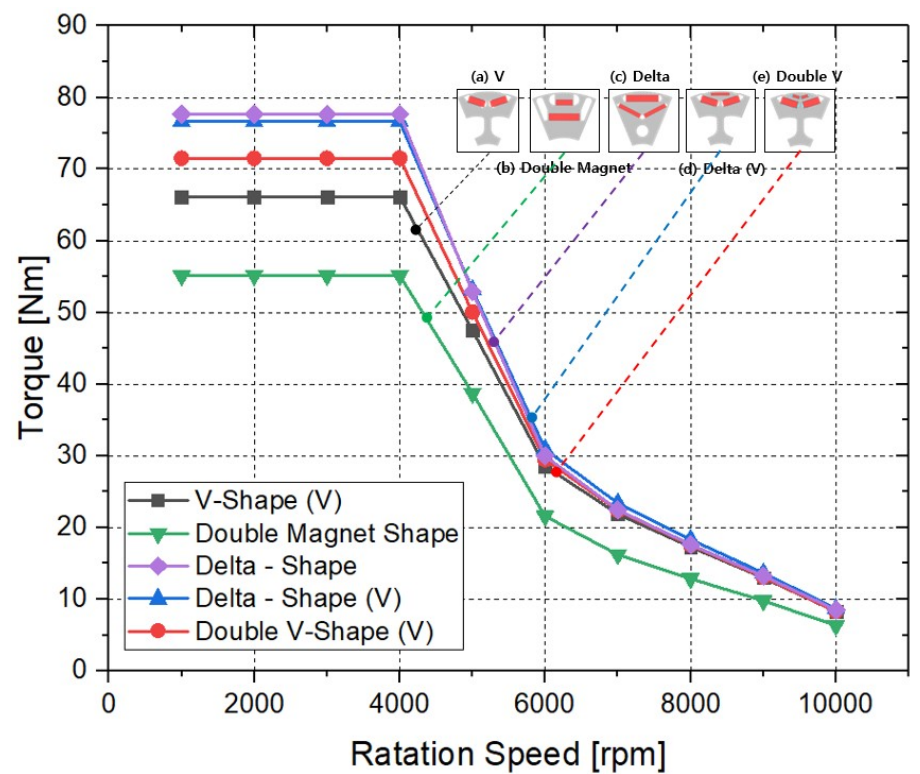

(a)

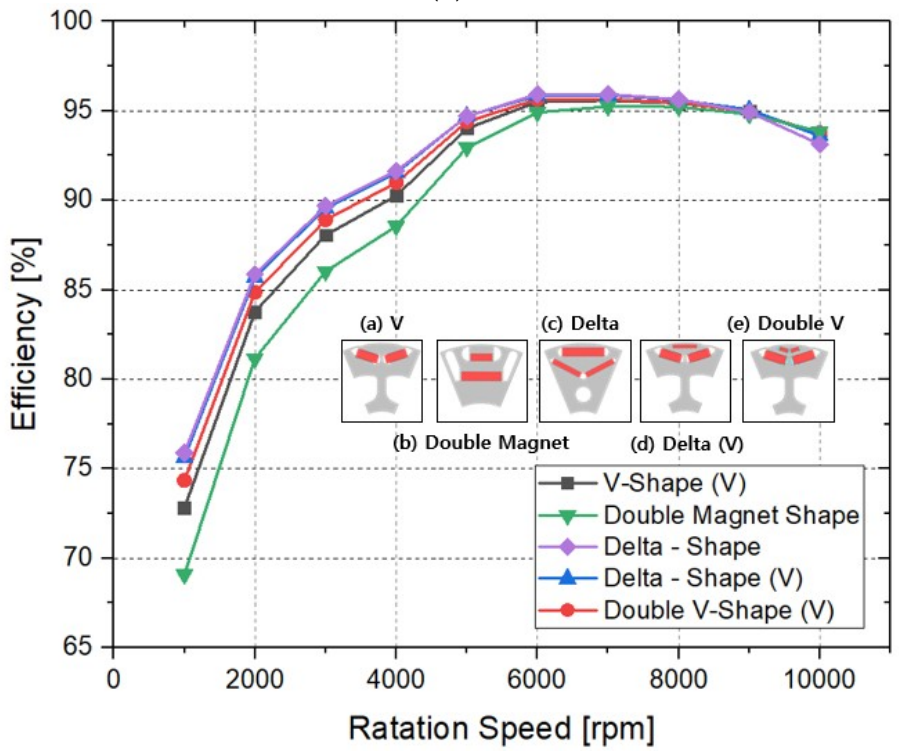

(b)

Figure 6. Current analysis of torque, ripple, efficiency comparison, and magnetic flux density at $0^{\circ}$ of phase angle: (a) Comparison of torque according to speed; (b) Comparison of efficiency according to speed.

Table 7. Comparison of speed-torque characteristics according to rotor shapes (phase angle of $40^{\circ}$ ).

\begin{tabular}{cccccc}
\hline RPM & $\begin{array}{c}\text { V Shape } \\
\text { (Manufacturer } \\
\mathbf{T})(\mathbf{N m})\end{array}$ & $\begin{array}{c}\text { Double } \\
\text { Magnet-Shape } \\
\text { (Manufacturer V) } \\
\mathbf{( N m )}\end{array}$ & $\begin{array}{c}\text { Delta Shape } \\
\text { (Manufacturer } \\
\mathbf{N}) \mathbf{( N m )}\end{array}$ & $\begin{array}{c}\text { Improved Model } \\
\text { (T+N Delta Shape) } \\
\text { (Nm) }\end{array}$ & $\begin{array}{c}\text { Improved Model } \\
\text { (T+V Double } \\
\text { V-Shape) (Nm) }\end{array}$ \\
\hline 1000 & 107.07544 & 84.50443 & 104.66107 & 109.14068 & 107.98762 \\
2000 & 107.06992 & 84.50021 & 104.66051 & 109.13429 & 107.98497 \\
3000 & 107.07162 & 84.49209 & 104.65735 & 109.13434 & 107.98034 \\
4000 & 107.06842 & 84.50367 & 104.6514 & 109.13934 & 107.97648 \\
5000 & 70.46591 & 54.01324 & 64.72424 & 70.05181 & 69.94164 \\
6000 & 35.90096 & 28.13232 & 32.53424 & 35.60729 & 35.38056 \\
7000 & 25.0925 & 20.39196 & 23.34639 & 25.08518 & 24.78409 \\
8000 & 18.50735 & 15.46581 & 17.69671 & 18.6181 & 18.32714 \\
9000 & 12.98148 & 10.91558 & 12.77176 & 13.1783 & 7.81597 \\
10,000 & 7.63406 & 6.34526 & 7.66694 & & 7.61829 \\
\hline
\end{tabular}




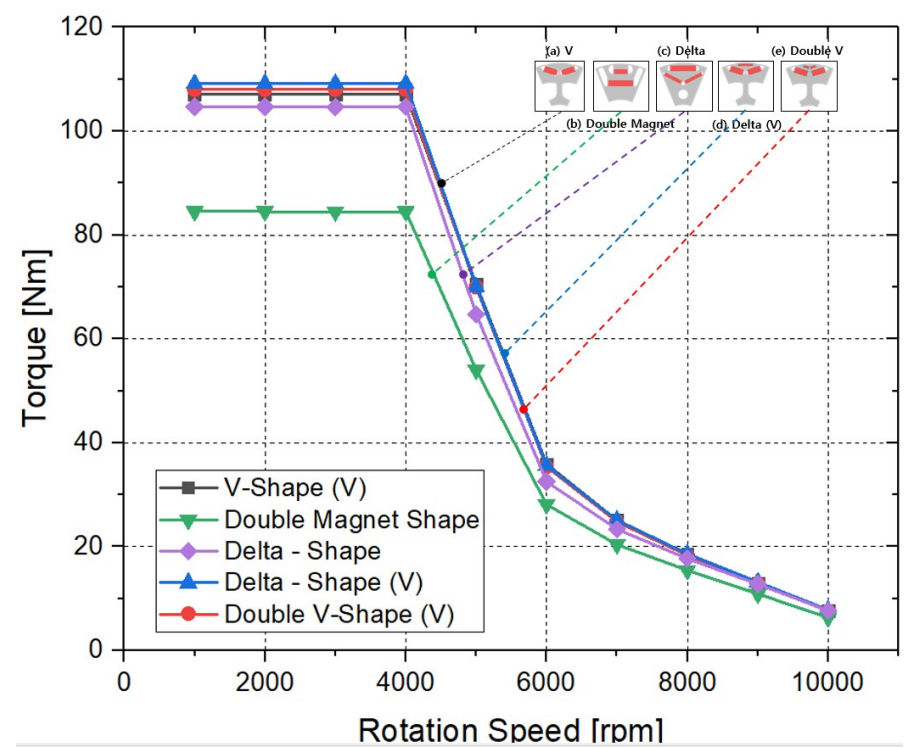

(a)

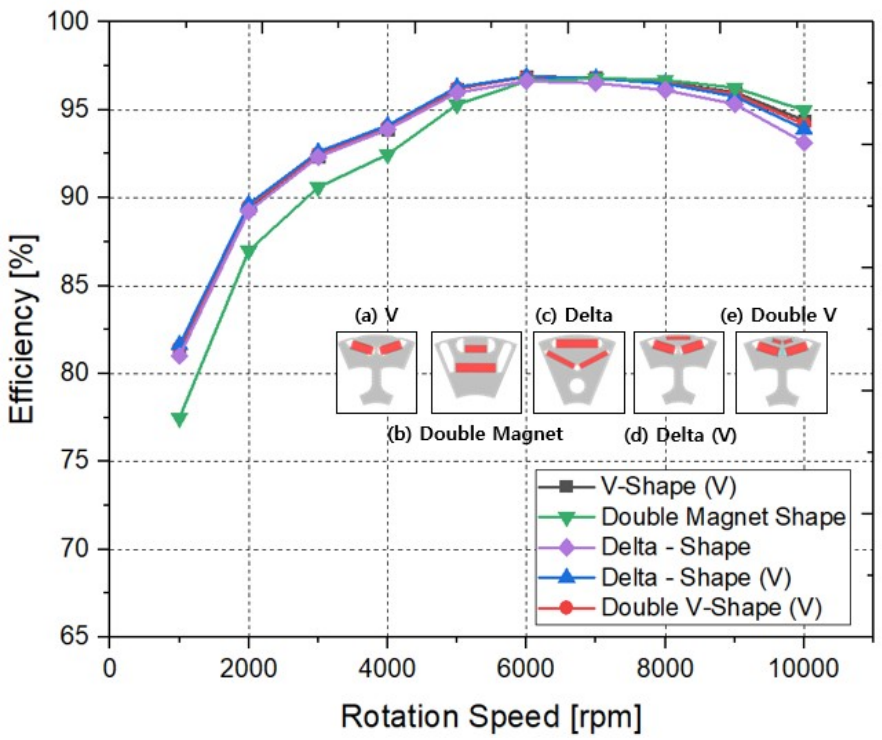

(b)

Figure 7. Analysis of torque and efficiency according to speed (phase angle controlled at $40^{\circ}$ ): (a) Comparison of torque according to speed (phase angle controlled at $40^{\circ}$ ); (b) Comparison of efficiency according to speed (phase angle controlled at $40^{\circ}$ ).

\subsection{Comparison of Power and Other Factors}

The manufacturing cost is mostly influenced by magnet shape and volume of the permanent magnet. As discussed, the main goal of this study was to increase manufacturing efficiency and decrease the effort and time needed for selection of the design concept. Therefore, in order to achieve MTPA with a minimum volume of motor, optimization of the rotor shape and reduction of magnet volume are important considerations in rotor design.

Figure 8 shows a comparison between power and other factors, based on previous analyses. As shown in Figure 8a, the double magnet shape had the lowest power, reflecting the lowest torque; the delta shape was the highest-power rotor shape. Except the double magnet shape, the comparison shows that power and manufacturing cost have a linear proportional relationship, because of complicated shapes and relatively high magnet volumes. Based on Figure $8 \mathrm{a}, \mathrm{b}$ shows a comparison of efficiency and power. Mechanical power output is calculated based on the torque and speed required, and 
electric motor efficiency is the ratio between output power and input power. Therefore, efficiency is mainly related to power, and Figure $8 \mathbf{b}$ shows a linear proportional relationship between power and efficiency.

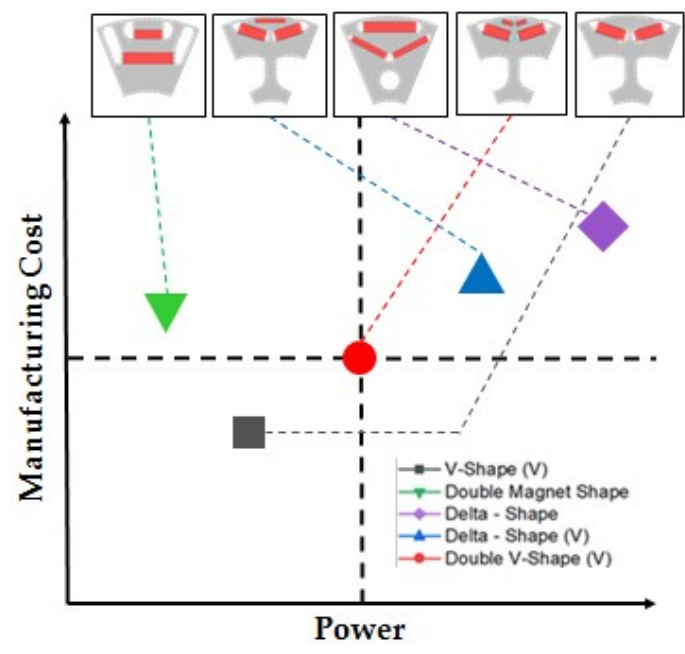

(a)

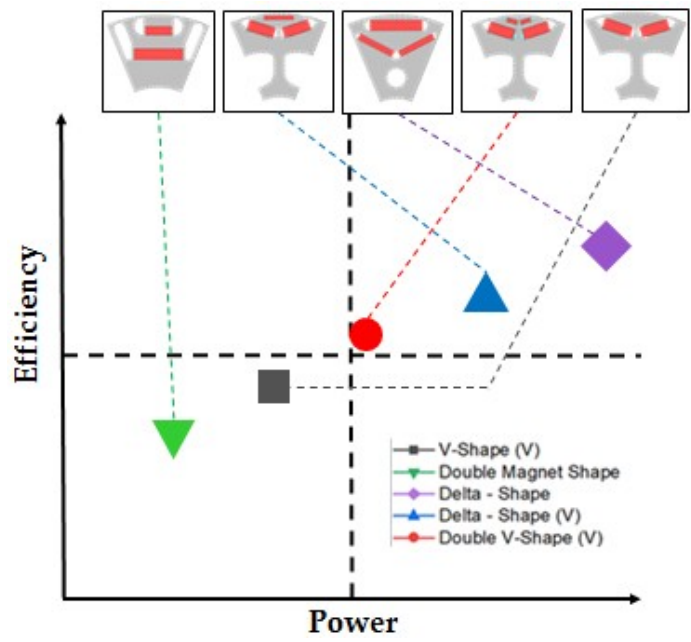

(b)

Figure 8. Comparison of power and other factors: (a) Comparison of manufacturing cost and power; (b) Comparison of efficiency and power.

\section{Conclusions}

This study analyzed the design and electromechanical properties of IMP motors for electric vehicles as a function of rotor shape; various factors (e.g., speed, torque, torque ripple and B-EMF voltage) were compared. The main goal of this study was to reduce the time required to design a rotor with the maximum power density for an IPM motor. The findings of this study will be useful for the confined space typical of EVs. Further study will fabricate an actual V-shaped rotor and verify the reliability of the electromagnetic analysis.

The sizes of outer diameters were fixed for both rotors and stators. The same stator shape and winding design was applied. Different arrangements of magnets were adopted for each rotor shape in order to obtain various results in speed, torque, efficiency, ripple, etc. In order to analyze the impact of both the $\mathrm{d}$ - and q-axis, the current of the q-axis was controlled at zero and the electromagnetic characteristics due to the $\mathrm{d}$-axis were examined. The delta shape from manufacturer $\mathrm{N}$ had the highest torque $(77.65 \mathrm{Nm})$ up to a rotation speed of $4000 \mathrm{rpm}$, and a higher torque by about $1 \mathrm{Nm}$ between 5000 and $10,000 \mathrm{rpm}$.

The impact of the q-axis was analyzed by applying a current phase angle of $40^{\circ}$. When the current phase angle was controlled, magnet torques and reluctance torques were combined, which enabled us to identify the maximum torque. The improved double $\mathrm{V}$ shape from manufacturer $\mathrm{T}$ had the best torque $(107.98 \mathrm{Nm})$. The $\mathrm{V}$ shape from manufacturer $\mathrm{T}$ showed higher torques at rotational speeds of $5000-10,000 \mathrm{rpm}$. In addition, the $\mathrm{V}$ shape had a magnet volume of $52,464 \mathrm{~mm}^{3}$, while the improved double $\mathrm{V}$ shape had a higher magnet volume of $60,736 \mathrm{~mm}^{3}$, indicating that the V-shape, with $13.6 \%$ less magnet volume, would be more advantageous for reducing the price of a motor.

Author Contributions: Conceptualization, M.-H.H. and H.-R.C.; Data curation, D.-H.K. and J.-H.H.; Formal analysis, M.-H.H.; Supervision, H.-R.C.; Validation, D.-H.K. and J.-H.H.; Visualization, M.-H.H.; Writing-original draft, M.-H.H.; Writing-review \& editing, H.-R.C.

Funding: This research was funded by the support of the Korea Institute of Industrial Technology as "Variable Architecture Powertrain Platform and Self-driving Factor Technology Development for Industrial EV Self-driving Vehicle" KITECH EO-18-0020.

Conflicts of Interest: The authors declare no conflicts of interest. 


\section{References}

1. De Santiago, J.; Bernhoff, H.; Ekergård, B.; Eriksson, S.; Ferhatovic, S.; Waters, R.; Leijon, M. Electrical motor drivelines in commercial all-electric vehicles: A review. IEEE Trans. Veh. Technol. 2012, 61, 475-484. [CrossRef]

2. Bazzi, A. Electric machines and energy storage technologies in EVs and HEVs for over a century. In Proceedings of the IEEE International Electric Machines \& Drives Conference, Chicago, IL, USA, 12-15 May 2013.

3. Zhu, Z.Q.; Howe, D. Electrical machines and drives for electric, hybrid, and fuel cell vehicles. Proc. IEEE 2007, 95, 746-765. [CrossRef]

4. Miyama, Y.; Hijikata, H.; Sakai, Y.; Akatsu, K.; Arita, H.; Daikoku, A. Variable characteristics technique on permanent magnet motor for electric vehicles traction system. In Proceedings of the 2015 IEEE International Electric Machines \& Drives Conference (IEMDC), Coeur d'Alene, ID, USA, 10-13 May 2015.

5. Yang, Y.; Arshad-Ali, K.; Roeleveld, J.; Emadi, A. State-of-the-art electrified powertrains: Hybrid, plug-in hybrid, and electric vehicles. Int. J. Powertrains 2016. [CrossRef]

6. Wang, A.; Li, H.; Lu, W.; Zhao, H. Influence of skewed and segmented magnet rotor on IPM machine performance and ripple torque for electric traction. In Proceedings of the IEEE International Electric Machines and Drives Conference, Miami, FL, USA, 3-6 May 2009.

7. Yang, Y.; Schofield, N.; Emadi, A. Integrated Electro-Mechanical Double-Rotor Compound Hybrid Transmissions for Hybrid Electric Vehicles. IEEE Trans. Veh. Technol. 2016. [CrossRef]

8. Lee, B.; Kim, K.; Jung, J.; Kim, Y. Temperature Estimation of IPMSM using Thermal Equivalent Circuit. IEEE Trans. Magn. 2016, 48, 2949-2952. [CrossRef]

9. Miller, T.J.E., Jr. Hendershot: Design of Brushless Permanent Magnet Machines; Magna Physics Corporation: Hillsboro, OH, USA, 1991.

10. Zhang, Y.; Cao, W.P.; Morrow, J. Interior Permanent Magnet Motor Parameter and Torque Ripple Analysis for EV Traction. In Proceedings of the 2015 IEEE International Conference on Applied Superconductivity and Electromagnetic Devices (ASEMD), Shanghai, China, 20-23 November 2015.

11. Kioumarsi, A.; Moallem, M.; Fahimi, B. Mitigation of Torque Ripple in Interior Permanent Magnet Motors by Optimal Shape Design. IEEE Trans. Magn. 2006, 42, 3708-3710. [CrossRef]

12. Yang, Y.; Castano, S.; Yang, R.; Kasprzak, M.; Bilgin, B.; Sathyan, A.; Dadkhah, H.; Emadi, A. Design and Comparison of Interior Permanent Magnet Motor Topologies for Traction Application. IEEE Trans. Transp. Electrif. 2017, 3, 4-9. [CrossRef]

13. Liu, X.; Lin, Q.; Fu, W. Optimal Design of Permanent Magnet Arrangement in Synchronous Motors. Energies 2017, 10, 1700. [CrossRef]

14. Wang, A.; Jia, Y.; Soong, W.L. Comparison of Five Topologies for an Interior Permanent-Magnet Machine for a Hybrid Electric Vehicle. IEEE Trans. Magn. 2011, 47, 3606-3609. [CrossRef]

15. Ma, F.; Yin, H.; Wei, L.; Tian, G.; Gao, H. Design and Optimization of IPM Motor Considering Flux Weakening Capability and Vibration for Electric Vehicle Applications. Sustainability 2018, 10, 1533. [CrossRef]

16. Soleimani, J.; Vahedi, A.; Mirimani, S.M. Inner permanent magnet synchronous machine optimization for HEV traction drive application in order to achieve maximum torque per ampere. Iran. J. Electr. Electron. Eng. 2011, 7, 241-247.

17. Ohnishi, T.; Takahashi, N. Optimal design of efficient IPM motor using finite element method. IEEE Trans. Magn. 2000, 36, 3537-3539. [CrossRef]

18. Takahashi, N.; Natsumeda, M.; Muramatsu, K.; Yamada, C.; Ogawa, M.; Kobayashi, S.; Kuwabara, T. Optimization of permanent magnet type of retarder using 3-D finite element method and direct search method. IEEE Trans. Magn. 1998, 34, 2996-2999. [CrossRef]

19. Wu, S.; Tian, L.; Cui, S. A comparative study of the interior permanent magnet electrical machine's rotor configurations for a single shaft hybrid electric bus. In Proceedings of the 2008 IEEE Vehicle Power and Propulsion Conference, Harbin, China, 3-5 September 2008. [CrossRef]

20. Sorgdrager, A.J.; Grobler, A.J. Influence of magnet size and rotor topology on the air-gap flux density of a radial flux PMSM. In Proceedings of the 2013 IEEE International Conference on Industrial Technology (ICIT), Cape Town, South Africa, 25-28 February 2013. [CrossRef] 
21. Kim, T.; Chang, J. Influence of Cogging Torque Reduction Method on Torque Ripple in a Surface-Mounted Permanent Magnet Synchronous Motor. J. Magn. 2012, 17, 111-113. [CrossRef]

22. Kim, J.; Seo, J.; Jung, H.; Won, C. Analysis and Design of a Novel-Shape Permanent Magnet Synchronous Motor for Minimization of Torque Ripple and Iron Loss. J. Magn. 2014, 4, 413-415. [CrossRef]

23. Kahourzade, S.; Mahmoudi, A.; Abdul Rahim, N.; Ping, H. Sizing equation and Finite Element Analysis optimum design of axial-flux permanent-magnet motor for electric vehicle direct drive. In Proceedings of the 2012 IEEE International Power Engineering and Optimization Conference, Melaka, Malaysia, 6-7 June 2012.

24. Mahmoudi, A.; Rahim, N.A.; Ping, H.W. Axial-flux permanent-magnet motor design for electric vehicle direct drive using sizing equation and finite element analysis. Prog. Electromagn. Res. 2012, 122, 467-496. [CrossRef]

25. Lukic, S.M.; Emado, A. Modeling of electric machines for automotive applications using efficiency maps. In Proceedings of the Electrical Insulation Conference and Electrical Manufacturing and Coil Winding Technology Conference (Cat. No.03CH37480), Indianapolis, IN, USA, 25-28 February 2003. [CrossRef]

(C) 2018 by the authors. Licensee MDPI, Basel, Switzerland. This article is an open access article distributed under the terms and conditions of the Creative Commons Attribution (CC BY) license (http://creativecommons.org/licenses/by/4.0/). 